\title{
Neoadjuvant modified TPF (docetaxel, cisplatin, fluorouracil) for patients unfit to standard TPF in locally advanced head and neck squamous cell carcinoma: a study of $\mathbf{4 8}$ patients
}

\author{
Jérôme Fayette ${ }^{1}$, Clara Fontaine-Delaruelle ${ }^{1}$, Alexis Ambrun ${ }^{2}$, Clémentine Daveau ${ }^{3}$, \\ Marc Poupart ${ }^{2}$, Antoine Ramade ${ }^{3}$, Philippe Zrounba ${ }^{4}$, Eve-Marie Neidhardt ${ }^{1}$, Julien \\ Péron $^{5,6}$, Alpha Diallo7 and Philippe Céruse ${ }^{3,7}$ \\ ${ }^{1}$ Department of Medicine, Léon Bérard Center, University of Lyon, Lyon, France \\ 2 Department of Surgery, Croix-Rousse Hospital, University of Lyon, Lyon, France \\ ${ }^{3}$ Department of Surgery, Edouard Herriot Hospital, University of Lyon, Lyon, France \\ ${ }^{4}$ Department of Surgery, Léon Bérard Center, University of Lyon, Lyon, France \\ ${ }^{5}$ Department of Medical Oncology, Institut du Cancer des Hospices Civils de Lyon, Centre Hospitalier Lyon-Sud, University \\ of Lyon, Pierre-Bénite, France \\ ${ }^{6}$ CNRS-UMR 5558, Biometry and Evolutive Biology Laboratory, Health and Biostatistics Team, Villeurbanne, France \\ ${ }^{7}$ Department of Surgery, Lyon Sud Hospital Center, University of Lyon, Pierre-Bénite, France \\ Correspondence to: Jérôme Fayette, email: jerome.fayette@lyon.unicancer.fr \\ Keywords: TPF, head and neck cancer, induction, cisplatin, frail patients \\ Received: January 26, $2016 \quad$ Accepted: April 16, $2016 \quad$ Published: April 22, 2016
}

\section{ABSTRACT}

TPF (docetaxel, cisplatin, fluorouracil) is the standard chemotherapy used for induction in locally advanced head and neck squamous cell carcinoma (LAHNSCC). Its toxicity limits it to younger patients with good functional status and without significant comorbidity. Since modified TPF (MTPF) demonstrated higher tolerability with similar efficacy in gastric cancer, we tested this scheme on frail patients.

From July 2010 to July 2014, the files of the 48 patients treated for LAHNSCC with $\mathrm{mTPF}$ in three French institutions were retrospectively collected.

mTPF was chosen because of age $>70$ years, or severe denutrition, or PS $>1$, or severe comorbidities or after severe toxicity of standard TPF. During the first 4 cycles, 2 patients died, 14 secondary hospitalizations were required and 10 patients stopped treatment due to no lethal toxicity. Two patients died during radiotherapy.

The response rate was $83 \%$ ( $19 \%$ complete response). With a median follow-up of 15.2 months, 4 patients died during treatment, 8 died of non-head and neck cancer related disorders, 18 progressed (17 deaths) and 18 were free of disease. The median overall survival was 18.5 months (95\% IC: 16.9-30.0).

mTPF is effective in terms of response rate compared with the standard TPF and could become a new option in induction for frail patients with LAHNSCC.

\section{INTRODUCTION}

For locally advanced head and neck squamous cell carcinoma (LAHNSCC), radiotherapy potentiated by cisplatin remains a standard attested by a large metaanalysis [1]. Induction chemotherapy by PF (cisplatin and fluorouracil $(5 \mathrm{FU})$ ) increases overall survival, but at a lower level than chemoradiotherapy. TPF (docetaxel, cisplatin and 5FU) as induction chemotherapy is superior to PF $[2,3]$. Then, TPF followed by radiotherapy or chemoradiotherapy is a valid therapeutic option but still largely debated. All guidelines are ancient (ESMO guidelines were published in 2010) and do not take into account recent data. None of the four direct comparisons between TPF followed by radiotherapy and exclusive chemoradiotherapy could demonstrate any significantly superior strategy [4-7]. TPF is the gold standard for larynx preservation [8]. 
TPF is toxic and should be saved for patients in good general condition: performance status 0 or 1 , no loss of weight $>10 \%$, no severe comorbidities, age $<70$ years.

Several of our patients met one of these criteria and could not receive TPF. Due to their fragility or to avoid mutilation, they were not operated on in first intent. Also due to their fragility, definitive chemoradiotherapy (even with cetuximab) was objected to by the radiotherapist. Radiotherapy alone is inferior to induction chemotherapy followed by radiotherapy. So we needed a specific induction chemotherapy.

In metastatic gastric cancer, TPF is a standard. Due to its toxicities, a randomized phase II study compared standard TPF (T and P $75 \mathrm{mg} / \mathrm{m}^{2} \mathrm{~d} 1, \mathrm{~F} 750 \mathrm{mg} / \mathrm{m}^{2} / \mathrm{d} \mathrm{d} 1$ to $\mathrm{d} 5$, every 3 weeks) and modified TPF (mTPF, T and P 40 $\mathrm{mg} / \mathrm{m}^{2} \mathrm{~d} 1$, leucovorin $400 \mathrm{mg} / \mathrm{m}^{2}$ followed by a bolus of F $400 \mathrm{mg} / \mathrm{m}^{2}$ then $1000 \mathrm{mg} / \mathrm{m}^{2} / \mathrm{d}, \mathrm{d} 1-2$, every 2 weeks). The tolerability was better with mTPF: with $6 \%$ vs $17 \%$ of febrile neutropenia, and $3 \%$ vs $20 \%$ of grade $3-4$ nausea/ vomiting. Furthermore, overall survival was in favor of mTPF with 18.8 months vs 12.6 months $(p=0.007)$ [9].

So after these promising results we decided to give $\mathrm{MTPF}$ to patients who had received standard TPF and experienced a great toxicity. We observed a good tolerability with apparently similar efficacy. We thus drafted a prospective phase II study and submitted it for public financing. However we were not selected and since all the drugs were generics, we could not obtain industrial financing. So we used this protocol for patients for whom a multidisciplinary team had chosen induction chemotherapy and who were unfit to standard TPF because we thought it better than palliative chemotherapy. Seeing these good results, we decided to collect the data of all our patients treated by mTPF in induction chemotherapy over a period of 4 years to show its tolerability and efficacy in fragile patients.

\section{PATIENTS AND METHODS}

\section{Data collection}

We retrospectively reviewed the files of all patients with histologically confirmed LAHNSCC for whom a decision of neoadjuvant chemotherapy was made by a multidisciplinary board but who were unfit for TPF. After the MTPF for gastric cancer was presented, they received $\mathrm{mTPF}$ in three institutions (Léon Bérard Center, Edouard Herriot Hospital, Croix-Rousse Hospital) between July 2010 and July 2014. Most patients had refused radical surgery at first, and were unfit for exclusive chemoradiotherapy. Tumors were classified using the UICC staging system [16].

Patient data were collected in accordance with the CNIL rules (the French authority for the protection of patient data) and kept anonymous.

\section{Treatment}

mTPF consisted of docetaxel and cisplatin at $40 \mathrm{mg} /$ $\mathrm{m}^{2}$ each on day 1 , leucovorin $400 \mathrm{mg} / \mathrm{m}^{2}$ followed by a bolus of Fluorouracil (5FU) at $400 \mathrm{mg} / \mathrm{m}^{2}$ then $1000 \mathrm{mg} /$ $\mathrm{m}^{2} / \mathrm{d}, \mathrm{d} 1-2$, every 2 weeks. All patients received adequate antiemetic prophylaxis and prednisolone $(50 \mathrm{mg}$, orally, twice a day for three days, starting on the morning before chemotherapy) to prevent hypersensitivity reactions and reduce docetaxel-related skin toxicity and fluid retention. Granulocyte colony-stimulating factor (G-CSF) was administered for primary prophylaxis, from day 4 for three days. No antibiotic was administered prophylactically. The number of planned cycles varied from 3 to 12 .

After mTPF, and according to multidisciplinary decisions, patients underwent surgery (neck dissection and/or tumor surgery) followed by radiotherapy within three to seven weeks of completion of chemotherapy or surgery. Radiation was delivered over a seven-week period using conventional fractionation (total dose of 66 to 70 Gy). Radiotherapy was administered alone if the patient was judged unsuitable for potentiation or was potentiated with weekly cisplatin $\left(40 \mathrm{mg} / \mathrm{m}^{2}\right)$ or cetuximab $(400$ $\mathrm{mg} / \mathrm{m}^{2}$ one week before radiotherapy, then $250 \mathrm{mg} / \mathrm{m}^{2}$ weekly).

\section{Assessment}

Tumor responses were evaluated according to RECIST 1.1 criteria. Patients had cervical and thoracic CTs before treatment and after one or two months of chemotherapy. Patients with hypopharyngeal or laryngeal cancer underwent another panendoscopy.

\section{Statistical analysis}

The response rate was estimated as being the proportion of patients who achieved complete or partial response out of the total number of patients who received at least one cycle of mTPF. Overall survival (OS) was defined as the time from the date of diagnosis to the date of death or to the date of the last follow-up visit for surviving patients (censored cases). Time to relapse (TTR) was defined as the time from the date of diagnosis to the date of recurrence. Survival estimates were calculated using the Kaplan-Meier method. The analysis was performed with SAS (version 9.2). 
Table 1: Patient characteristics at onset of mTPF $(n=48)$

\begin{tabular}{|c|c|c|}
\hline & $N$ & $\%$ \\
\hline Median age, years [range] & \multicolumn{2}{|c|}{$59[48-85]$} \\
\hline \multicolumn{3}{|l|}{ Sex } \\
\hline Female & 7 & 15 \\
\hline Male & 41 & 85 \\
\hline \multicolumn{3}{|l|}{ Tumor site at initial diagnosis } \\
\hline Oral cavity & 8 & 17 \\
\hline Oropharynx & 18 & 38 \\
\hline Hypopharynx & 15 & 31 \\
\hline Larynx & 6 & 12 \\
\hline Neck node without primary & 1 & 2 \\
\hline \multicolumn{3}{|l|}{ Tumor stage at initial diagnosis } \\
\hline II & 1 & 2 \\
\hline III & 6 & 13 \\
\hline $\mathrm{IVa}$ & 29 & 60 \\
\hline $\mathrm{IVb}$ & 12 & 25 \\
\hline \multicolumn{3}{|l|}{ Intent of treatment } \\
\hline Operable patient, organ preservation & 28 & 58 \\
\hline Inoperable patient, palliation & 20 & 42 \\
\hline \multicolumn{3}{|l|}{ PS at the onset of mTPF } \\
\hline 0 & 12 & 25 \\
\hline 1 & 17 & 35 \\
\hline 2 & 16 & 33 \\
\hline 3 & 3 & 6 \\
\hline \multicolumn{3}{|c|}{ Reason for choice of mTPF instead of standard TPF } \\
\hline Age $>70$ years & 10 & 21 \\
\hline $\mathrm{PS}>1$ & 19 & 40 \\
\hline Loss of weight $>10 \%$ & 7 & 15 \\
\hline Severe Comorbidities & 7 & 15 \\
\hline Toxicity after a first cycle of standard TPF & 4 & 8 \\
\hline Unknown & 1 & 2 \\
\hline
\end{tabular}

\section{RESULTS}

\section{Patient characteristics}

Between July 2010 and July 2014, 48 patients with histologically confirmed locally advanced or metastatic HNSCC were treated with MTPF in the three French institutions taking part in the study. Patient characteristics are summarized in Table 1 . They were predominantly men $(n=41 ; 85 \%)$ with a median age of 59 years (range: 48-85) at onset of mTPF. For all these patients the multidisciplinary team recommended neoadjuvant chemotherapy. But they were unfit for standard TPF, due to age $>70$ years $(n=10 ; 21 \%)$, PS $>1(n=19 ; 40 \%)$, loss of weight $>10 \%(n=7 ; 15 \%)$ or severe comorbidities ( $n=7 ; 15 \%$ : chronic obstructive pneumopathy, history of acute renal failure, concomitant rectal cancer, liver transplantation, adrenal insufficiency, severe arteriopathy, psychiatric disorders). Four patients had a sever toxicity after the first standard TPF (one febrile neutropenia, two colitis and one severe asthenia) and we decided to pursue with $\mathrm{mTPF}(n=4 ; 8 \%)$. One patient received mTPF for unknown reason.

The two most common primary tumor sites were the oropharynx $(n=18 ; 38 \%)$ and the hypopharynx $(n=$ $15 ; 31 \%)$. Twenty patients $(42 \%)$ were judged inoperable. Overall, tumors were advanced at the time of diagnosis, with $29(60 \%)$ and $12(25 \%)$ patients with stage IVa or $\mathrm{IVb}$ tumors respectively. 
Table 2: Delivery and toxicity of mTPF (median number of cycles: 4; total number of cycles: 214)

\begin{tabular}{|l|l|l|l|l|}
\hline Toxicities & $\begin{array}{l}\text { First cycle } \\
(\boldsymbol{n}=\mathbf{4 8})\end{array}$ & $\begin{array}{l}\text { Second cycle } \\
(\boldsymbol{n}=\mathbf{4 4 )}\end{array}$ & $\begin{array}{l}\text { Third cycle } \\
(\boldsymbol{n}=\mathbf{3 8})\end{array}$ & $\begin{array}{l}\text { Fourth cycle } \\
(\boldsymbol{n}=\mathbf{2 7})\end{array}$ \\
\hline Febrile neutropenia & $2(4 \%)$ & 0 & $1(3 \%)$ & $1(4 \%)$ \\
\hline Diarrhea (gr 3-4) & $3(6 \%)$ & $1(2 \%)$ & $2(5 \%)$ & 0 \\
\hline $\begin{array}{l}\text { Secondary } \\
\text { hospitalization }\end{array}$ & $5(10 \%)$ & $4(9 \%)$ & $2(5 \%)$ & $3(8 \%)$ \\
\hline $\begin{array}{l}\text { Transient creatinine } \\
\text { elevation }\end{array}$ & $4(8 \%)$ & $5(11 \%)$ & $2(5 \%)$ \\
\hline $\begin{array}{l}\text { Cause of } \\
\text { discontinuation }\end{array}$ & $\begin{array}{l}\text { interruptions for } \\
\text { toxicity }(8 \%)\end{array}$ & $\begin{array}{l}1 \text { death }(2 \%) \\
\text { interruptions for } \\
\text { toxicity }(8 \%)\end{array}$ & $\begin{array}{l}1 \text { death }(3 \%) \\
\text { interruptions for } \\
\text { toxicity }(5 \%)\end{array}$ & $\begin{array}{l}\text { Planned. } \\
\text { No toxicity }\end{array}$ \\
\hline
\end{tabular}

Table 3: Best response to $\mathrm{mTPF}$ and type of treatment after induction

\begin{tabular}{|c|c|c|}
\hline Best response to TPF & \multirow{2}{*}{$\frac{N}{40}$} & \multirow{2}{*}{$\begin{array}{l}\% \\
83 \\
\end{array}$} \\
\hline Overall response rate & & \\
\hline Complete response & 9 & 19 \\
\hline Partial response & 31 & 65 \\
\hline Stable disease & 5 & 10 \\
\hline Progressive disease & 1 & 2 \\
\hline Not evaluable & 2 & 4 \\
\hline Surgery of the tumor & 8 & 17 \\
\hline Mutilating & 4 & 8 \\
\hline Non-mutilating & 4 & 8 \\
\hline Node dissection (of whom 14 had only node dissection) & 20 & 42 \\
\hline Radiotherapy & 39 & 81 \\
\hline Exclusive & 22 & 46 \\
\hline Potentiated & 17 & 35 \\
\hline Weekly cisplatin & 8 & 17 \\
\hline Weekly cetuximab & 6 & 12 \\
\hline Unknown & 3 & 6 \\
\hline
\end{tabular}

\section{mTPF delivery and safety}

Data on mTPF delivery and toxicities are summarized in Table 2. The vast majority of patients were scheduled to receive 4 cycles of chemotherapy and the median number of cycles administered was 4 (range 1-12). In total 214 cycles were administered.

Two patients $(4 \%)$ died during chemotherapy and 10 patients $(21 \%)$ stopped treatment due to toxicity. The levels of febrile neutropenia or grade 3-4 diarrhea were very low: for example $2(4 \%)$ and $3(6 \%)$ respectively for the first cycle. The numbers of secondary hospitalizations were 5 (10\% of patients treated for this cycle), $4(9 \%), 2$
$(5 \%)$ and $3(8 \%)$ for the 4 first cycles respectively. For patients who pursued chemotherapy for more than 4 cycles, we did not observe particular toxicity.

\section{Efficacy of mTPF}

The overall response rate according to RECIST intent-to-treat criteria was $83 \%$, of which $19 \%$ were complete responses and 65\% partial responses (Table 3); $10 \%$ of patients had stable disease, and $2 \%$ progressed on treatment. 


\section{Treatments after mTPF}

After mTPF, $8(17 \%)$ patients had surgery, of whom $4(7 \%)$ had non-mutilating surgery and $4(8 \%)$ had mutilating surgery (due to insufficient response in operable patients). Neck dissection was performed on $20(42 \%)$ patients because of persistent nodal disease (of whom 14 had only neck dissection). Indeed in France we prefer to perform node dissection if large involvement before radiotherapy. After mTPF, 39 (81\%) patients were irradiated, $22(46 \%)$ without potentiation, and $17(35 \%)$ with potentiation. The type of potentiation was weekly cisplatin $\left(40 \mathrm{mg} / \mathrm{m}^{2}\right)$ for 8 patients and cetuximab for 6 patients (3 unknown). Four patients had temporary arrest of radiation (2 deaths, both potentiated -1 weekly cisplatin, 1 unknown- 2 others without potentiation) and all but the two dead received the planned cumulative dose of radiotherapy. In case of toxicity the potentation was stopped in order to favour the total dose of radiotherapy: $4 / 6$ patients with cetuximab, $2 / 8$ with weekly cisplatin and $1 / 3$ with unknown potentation had to stop potentiation.

\section{Survival data}

After a median follow-up of 15.2 months (range between 0.3 and 42 months), 18 (37.5\%) patients relapsed and 17 died, and 18 patients were alive with no evidence of disease. Four died during treatment, and 8 died of nonhead and neck cancer related disorders ( 2 cardiac failures, 2 secondary cancers - oesophagus, colorectal-, 3 unknown -probably cardiac failures, 1 anaphylaxis shock), due to the high fragility of these patients.

As shown in Figure 1, the median overall survival was 18.5 months (95\% IC: $16.9-30.0$ ).

Due to the frailty of these patients it seems more interesting to evaluate the median time to relapse instead of the progression-free survival. As shown in Figure 2, the median time to relapse was 22.2 months (95\% IC: 13.2 NR).

\section{DISCUSSION}

This retrospective study met its objectives and demonstrated tolerability and efficacy of mTPF in fragile patients with a LAHNSCC. Even if of course no direct comparison can be made between different studies, we should discuss our results in the light of the three pivotal phase III trials of standard TPF $[2,3,10]$, and of our previously reported retrospective study of TPF by the same institutions in routine practice [11]. The patients were all PS 0-1 and had a median age of 53-57 years compared to $40 \%$ of patients who were at least PS 2 and had a median age of 59 years (and $21 \%$ of patients older than 70 years) in our study.
In terms of efficacy, at $83 \%$ the response rate of mTPF is similar to the $68-84 \%$ reported $[2,3,10]$. In terms of tolerability, with mTPF we observed only 2 toxic deaths (4\%) and 4 febrile neutropenia (8\%) despite 3 days of G-CSF. We did not use prophylactic ciprofloxacin because monotherapy with fluoroquinols induces a high level of bacterial mutations that lead to resistance and the expected duration of neutropenia is less than 7 days. On account of age and comorbidities, the use of G-CSF prophylaxis is recommended by ASCO guidelines but we probably chose too short a duration and for future treatments we will recommend at least 5 days of G-CSF. Because of our prudence with fragile patients treated by $\mathrm{mTPF}$, we interrupted treatment for $10(21 \%)$ of them (vs 6\% with standard TPF). The rate of secondary hospitalization (29\% vs 27\%) was similar to that in our previous study with TPF for fit patients [11]. 3 out of 4 patients who experienced severe acute toxicity to TPF could receive MTPF safely. The continuation of treatment is not compromised by mTPF since 39 patients $(82 \%)$ were irradiated, similar to other studies $[2,3,10]$.

What is the optimal number of mTPFcycles? In the pivotal studies patients received 3 to 4 cycles of TPF with a cumulative dose of cisplatin and docetaxel of 225-300 $\mathrm{mg} / \mathrm{m}^{2}$ for a duration of 2 to 3 months. So we propose 4 to 6 cycles of mTPF for the same length of time and doses ranging from 140 to $240 \mathrm{mg} / \mathrm{m}^{2}$. In our study, 5 and 3 patients received 8 and 12 cycles respectively on account of its good tolerability and efficacy in a context of severe comorbidities. So we decided to favour the quality of life and decided not to irradiate 5 patients and to delay the decision of radiotherapy for 3 others (radiation was finally performed after their health had generally improved).

The place of induction chemotherapy is still debated. Induction by TPF has demonstrated superiority to $\mathrm{PF}$ in terms of overall survival and laryngeal preservation and has become the standard treatment when induction is chosen $[2,3,10,12]$. TPF is largely accepted for larynx preservation with an impressive level of larynx dysfunction-free survival at 10 years of $63,7 \%$ [8].

For other localizations or for inoperable tumors, chemoradiation with cisplatin remains the standard. But guidelines are ancient (ESMO guidelines were published in 2010) and do not take into account the most recent data. Clearly our population could not receive radiotherapy potentiated by cisplatin every three weeks at the dose of $100 \mathrm{mg} / \mathrm{m} 2$. Similarly our radiotherapists objected to potentiation by cetuximab (that was not directly compared to cisplatin) due to its toxicity in frail patients with gross tumors in our experience. Since induction chemotherapy is superior to radiation alone [13] we then preferred induction chemotherapy before radiation.

No study has yet demonstrated superiority of chemoradiation versus induction followed by radiotherapy (eventually with potentiation). Four phase III studies failed 


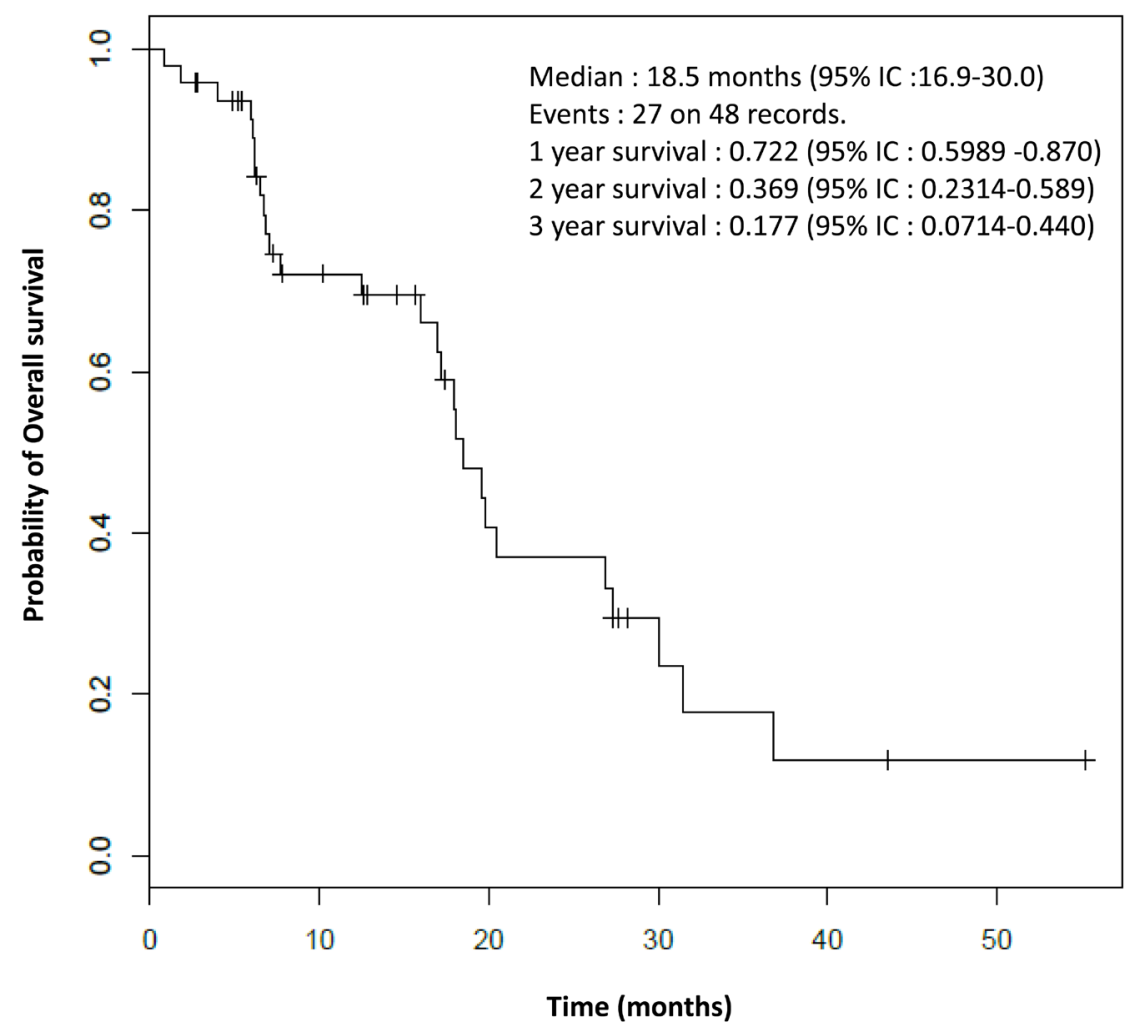

Figure 1: Overall survival.

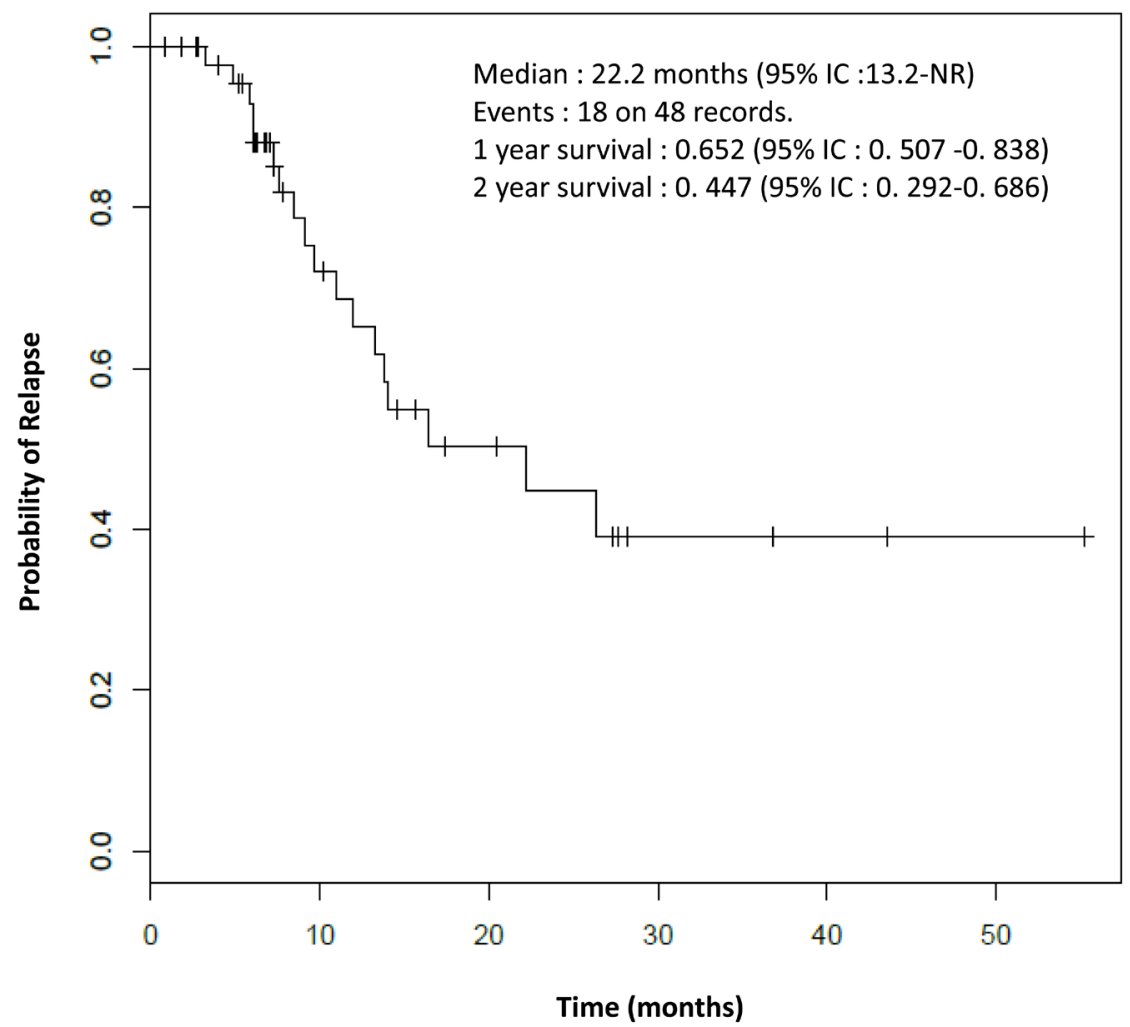

Figure 2: Time to relapse. 
to draw a conclusion mainly because of methodological problems. In the first trial the per-protocol analysis showed superiority of induction followed by chemoradiation but did not reach a statistical significance as intent to treat, due to high levels of toxicity [7]. In two others, only $50 \%$ of the planned patients were included and finally no statistical difference could be shown $[4,6]$. The last study compared four arms to take into account the role of cetuximab in combination with radiotherapy. Patients received TPF followed by chemoradiation or chemoradiation alone. For chemoradiation, patients received a potentiation by weekly cetuximab or by 2 cycles of cisplatin and 5FU. The data of patients irradiated with cisplatin or cetuximab were pooled to compare induction versus no induction: the median overall survival was significantly better with induction by TPF (53.3 months vs 30.3 months, HR $=0.72,95 \%$ IC $0.55-0.96, p=0.025)$ [5]. But since i) there is no direct demonstration of similar efficacy of potentiation by cisplatin or cetuximab, ii) the subgroup analysis of patients irradiated with cisplatin did not achieve significance, no definitive conclusion could be drawn.

In conclusion, our study demonstrated the safety of mTPF and its efficacy on response rate for patients unfit to TPF. mTPF could increase tolerability of induction chemotherapy for fit patients with similar efficacy and could increase compliance and efficacy of the entire sequence of treatment. Indeed induction proved superior to chemoradiation if the entire sequence could be administered [7].These encouraging results lead us to a randomized study for fit patients comparing $\mathrm{mTPF}$ and TPF.

\section{CONFLICTS OF INTEREST}

Dr. Philippe Ceruse is a member of the board of Merck-Serono.

Other authors have no conflict of interest.

\section{Authors' contributions}

JF contributed to the study design, patient selection, data collection, data analysis, and manuscript drafting and approval.

CFD, AA, CD, AD contributed to data collection.

JP contributed to data analysis. selection.

MP, AR, PZ, EMN, PC contributed to patient

All authors read and approved the final manuscript.

\section{REFERENCES}

1. Pignon JP, le Maitre A, Maillard E, Bourhis J. Metaanalysis of chemotherapy in head and neck cancer (MACHNC): an update on 93 randomised trials and 17,346 patients. Radiother Oncol. 2009; 92:4-14.
2. Posner MR, Hershock DM, Blajman CR, Mickiewicz E, Winquist E, Gorbounova V, Tjulandin S, Shin DM, Cullen K, Ervin TJ, Murphy BA, Raez LE, et al. Cisplatin and fluorouracil alone or with docetaxel in head and neck cancer. N Engl J Med. 2007; 357:1705-15.

3. Vermorken JB, Remenar E, van Herpen C, Gorlia T, Mesia R, Degardin M, Stewart JS, Jelic S, Betka J, Preiss JH, van den Weyngaert D, Awada A, et al. Cisplatin, fluorouracil, and docetaxel in unresectable head and neck cancer. N Engl J Med. 2007; 357:1695-704.

4. Cohen EE, Karrison TG, Kocherginsky M, Mueller J, Egan R, Huang CH, Brockstein BE, Agulnik MB, Mittal BB, Yunus F, Samant S, Raez LE, et al. Phase III randomized trial of induction chemotherapy in patients with N2 or N3 locally advanced head and neck cancer. J Clin Oncol. 2014; 32:2735-43.

5. Ghi MG, Paccagnella A, Ferrari D, Foa P, Rocca MC, Verri E, Morelli F, Azzarello G, D’Ambrosio C, Cruciani G, Guaraldi M, Massa E, et al. Concomitant chemoradiation (CRT) or cetuximab/RT (CET/RT) versus induction Docetaxel/ Cisplatin/5-Fluorouracil (TPF) followed by CRT or CET/RT in patients with Locally Advanced Squamous Cell Carcinoma of Head and Neck (LASCCHN). A randomized phase III factorial study (NCT01086826). 32 ed 2014. Abstr 6004.

6. Haddad R, O'Neill A, Rabinowits G, Tishler R, Khuri F, Adkins D, Clark J, Sarlis N, Lorch J, Beitler JJ, Limaye S, Riley S, et al. Induction chemotherapy followed by concurrent chemoradiotherapy (sequential chemoradiotherapy) versus concurrent chemoradiotherapy alone in locally advanced head and neck cancer (PARADIGM): a randomised phase 3 trial. Lancet Oncol. 2013; 14:257-64.

7. Hitt R, Grau JJ, Lopez-Pousa A, Berrocal A, Garcia-Giron C, Irigoyen A, Sastre J, Martinez-Trufero J, Brandariz Castelo JA, Verger E, Cruz-Hernandez JJ. A randomized phase III trial comparing induction chemotherapy followed by chemoradiotherapy versus chemoradiotherapy alone as treatment of unresectable head and neck cancer. Ann Oncol. 2014; 25:216-25.

8. Janoray G, Pointreau Y, Garaud P, Chapet S, Alfonsi M, Sire C, Tuchais C, Calais G. Long-term results of GORTEC 2000-01: A multicentric randomized phase III trial of induction chemotherapy with cisplatin plus 5-fluorouracil, with or without docetaxel, for larynx preservation. 33 ed 2015. Abstr 6002.

9. Shah MA, Janjigian YY, Stoller R, Shibata S, Kemeny M, Krishnamurthi S, Su YB, Ocean A, Capanu M, Mehrotra B, Ritch P, Henderson C, et al. Randomized Multicenter Phase II Study of Modified Docetaxel, Cisplatin, and Fluorouracil (DCF) Versus DCF Plus Growth Factor Support in Patients With Metastatic Gastric Adenocarcinoma: A Study of the US Gastric Cancer Consortium. J Clin Oncol. 2015; 20:3874-9. 
10. Pointreau Y, Garaud P, Chapet S, Sire C, Tuchais C, Tortochaux J, Faivre S, Guerrif S, Alfonsi M, Calais G. Randomized trial of induction chemotherapy with cisplatin and 5-fluorouracil with or without docetaxel for larynx preservation. J Natl Cancer Inst. 2009; 101:498-506.

11. Fayette J, Bonnin N, Ferlay C, Lallemant B, Ramade A, Favrel V, Zrounba P, Chabaud S, Pommier P, Poupart M, Ceruse P. Neoadjuvant TPF in locally advanced head and neck cancer can be followed by radiotherapy combined with cisplatin or cetuximab: a study of 157 patients. Anticancer Drugs. 2013; 24:623-9.
12. Blanchard P, Bourhis J, Lacas B, Posner MR, Vermorken JB, Hernandez JJ, Bourredjem A, Calais G, Paccagnella A, Hitt R, Pignon JP. Taxane-cisplatin-fluorouracil as induction chemotherapy in locally advanced head and neck cancers: an individual patient data meta-analysis of the meta-analysis of chemotherapy in head and neck cancer group. J Clin Oncol. 2013; 31:2854-60.

13. Forastiere AA, Goepfert H, Maor M, Pajak TF, Weber R, Morrison W, Glisson B, Trotti A, Ridge JA, Chao C, Peters $\mathrm{G}$, Lee DJ, et al. Concurrent chemotherapy and radiotherapy for organ preservation in advanced laryngeal cancer. N Engl J Med. 2003; 349:2091-8. 